\title{
ENRAIZAMENTO DE ESTACAS DE ESPÉCIES DE MARACUJAZEIRO (Passiflora spp.) NO INVERNO E NO VERÃO'
}

\author{
GIVANILDO RONCATTO², GERALDOCOSTANOGUEIRAFILHO33, CARLOS RUGGIERO4, \\ JOÃO CARLOS DE OLIVEIRA ${ }^{5}$, ANTÔNIOBALDO GERALDO MARTINS ${ }^{6}$
}

RESUMO - O maracujazeiro está entre as principais frutíferas cultivadas no País, mas apresenta limitações no cultivo, ocasionando baixa produtividade, que pode ser superada através do uso da estaquia, clonando as melhores matrizes de alta produtividade. Com isso, o objetivo desta pesquisa foi avaliar o potencial de enraizamento de estacas no inverno e no verão, utilizando as espécies comerciais ( $P$. edulis Sims f. flavicarpa Degener e $P$. alata Dryander) e os porta-enxertos (P. giberti N.E.Brown, $P$. nitida H.B.K. e $P$. setacea D.C.). Este experimento foi realizado no período de julho de 2001 a março de 2002, em câmara de nebulização intermitente, sob condições de telado (50\% de sombreamento). As estacas foram coletadas de plantas adultas oriundas do Banco de Germoplasma Ativo (BAG) do Departamento de Produção Vegetal da Faculdade de Ciências Agrárias e Veterinárias da Universidade Estadual Paulista, Jaboticabal-SP (FCAV/UNESP) e de pomares comerciais, em julho de 2001 e em janeiro de 2002. A estaquia foi feita com a coleta da parte intermediária de ramos em estádio de crescimento vegetativo, no inverno e no verão. As estacas herbáceas tinham aproximadamente $15 \mathrm{~cm}$ de comprimento, três nós e duas meias - folhas. As estacas foram tratadas com ácido indolbutírico (AIB) nas concentrações de 0; 500; 1.000 e 2.000mg. $\mathrm{L}^{-1}$, por cinco segundos, e plantadas em bandejas plásticas (40x30x10cm) com vermiculita de textura média, onde permaneceram por 60 dias. Houve influência do AIB e da época do ano no enraizamento, variando de acordo com a espécie. Sendo assim, $P$. giberti obteve o melhor desempenho em relação às demais espécies, com $73 \%$ de enraizamento no verão. A percentagem de enraizamento foi melhor para P. alata (58\%) e para P. nitida (40\%) no inverno e sem AIB. P. edulis f. flavicarpa enraizou apenas $23 \%$ no inverno, e $P$. setacea não enraizou. O número e o comprimento de raízes foram maiores no inverno. A sobrevivência de plantas não se diferenciou significativamente entre os tratamentos.

Termos para Indexação: AIB, P. edulis, P. alata, P. nitida, P. giberti, P. setacea.

\section{CUTTING ROOTING OF PASSION FRUIT PLANT SPECIES (Passiflora spp.) IN THE WINTER AND IN THE SUMMER}

\begin{abstract}
The passion fruit plant is among the leading fruit grown in the country, but it has limitations on the cultivation causing a low productivity, which can be overcome through the use of cutting, cloning the best matrices of high productivity. Thus, the objective of this research was to evaluate the potential for rooting of cuttings in the winter and in the summer, using the commercial species ( $P$. edulis Sims f. flavicarpa Degener and P. alata Dryander) and rootstocks (P. giberti N. E. Brown, $P$. nitida H.B.K. and $P$. setacea D.C.). This experiment was carried out from July 2001 to March 2002 in intermittent mist, under screenhouse conditions (50\% of shading). The cuttings were collected from adult plants from the Bank of Active Germplasm (BAG) of the Department of Plant Production of Veterinary and Agricultural Sciences of the Universidade Estadual Paulista, Jaboticabal-SP (FCAV / UNESP) and from commercial orchards on July 2001 and January 2002. The herbaceous cuttings were prepared with the intermediate part of branches collected in the growth stage in the winter and in the summer. The cuttings were approximately $15 \mathrm{~cm}$ long, with three nodes and two half leaves. The cuttings were treated with indolebutyric acid (IBA) at concentrations of 0, 500, 1000 and $2000 \mathrm{mg}^{-L^{-1}}$, for five seconds and planted in plastic trays $(40 \times 30 \times 10 \mathrm{~cm})$ with vermiculite of medium texture, where they remained for 60 days. There was influence both from IBA and the season on the rooting, varying according to the species. Therefore, $P$. giberti obtained the best performance in relation to other species, with $73 \%$ of rooting in the summer, while the percentage of rooting was best for the $P$. alata (58\%) and for the $P$. nitida (40\%) in the winter and without IBA. P. edulis f. flavicarpa rooted only $23 \%$ in the winter, and $P$. setacea did not root. Number and length of roots were higher in the winter. The survival of plants did not differ significantly among treatments.
\end{abstract}

Index Terms: IBA, . edulis, $P$. alata, $P$. nitida, P. giberti, P. setacea.

\footnotetext{
${ }^{1}$ (Trabalho 241-07). Recebido em: 04-10-2007. Aceito para publicação em: 28-08-2008.

${ }^{2}$ Pesquisador da Embrapa Acre. Rodovia BR 364 km 14, Zona Rural, Cep 69901180 Rio Branco-AC. E-mail: givanildo@cpafac.embrapa.br ${ }^{3}$ In memorian

${ }^{4}$ Eng.Agr.,Dr. Professor Titular - Depto.Produção Vegetal - Unesp/FCAV. Via de acesso Paulo Donato Castellane, s/n Cep 14884-900 Jaboticabal-SP. ruggiero@fcav.unesp.br

${ }^{5}$ Eng.Agr.,Dr. Professor Titular - Depto. Produção Vegetal/ Fitotecnia - Unesp/FCAV. Via de acesso Paulo Donato Castellane, s/n Cep 14884-900 Jaboticabal-SP. jocaoliv@fcav.unesp.br

${ }^{6}$ Eng.Agr.,Dr. Professor Assistente - Depto. Produção Vegetal - Unesp/FCAV. Via de acesso Paulo Donato Castellane, s/n Cep 14884-900 Jaboticabal-SP. baldo@fcav.unesp.br
} 


\section{INTRODUÇÃO}

O Brasil é o maior produtor mundial de maracujá, produzindo aproximadamente meio milhão de toneladas, numa área de 33 mil hectares, com o cultivo do maracujá-amarelo (Passiflora edulis Sims f. flavicarpa Degener) em 95\% dos plantios do País, enquanto o maracujá-doce (Passiflora alata Dryander) contribui com 5\% da área plantada. A Bahia é o Estado de maior produção nacional, com 140 mil toneladas, numa área de 11 mil hectares de maracujazeiro, e o Estado de São Paulo apresenta a sexta maior produção, com 41 mil toneladas em 2,3 mil hectares de área (IBGE, 2007).

Essa produção é destinada para consumo de frutas in natura e para a indústria de sucos, abastecendo o mercado interno. O maracujá-doce conquistou mercados restritos e de maior valor agregado, pela menor demanda de frutos.

Problemas intrínsecos da cultura do maracujazeiro dificultam sua expansão. A auto-incompatibilidade e a morte prematura de plantas apresentam-se como problemas de difícil solução, pois não se tem uma recomendação para o controle da morte prematura e a redução de indivíduos auto-incompatíveis. Atualmente, os pomares são propagados por semente, método que dificulta a superação dessas importantes limitações.

Outro aspecto a ser salientado é a reprodução assexual de espécies silvestres, para uso como porta-enxerto. Essas espécies são resistentes ou tolerantes a doenças, principalmente à morte prematura de plantas, às pragas, à seca e a nematóides (Ruggiero \& Oliveira, 1998). Dessa forma, a estaquia complementada pela enxertia, como é utilizada na videira, contribuiria na expansão da cultura, superando mais uma importante limitação.

Com isso, a estaquia ganha importância como método alternativo ao de sementes, proporcionando a multiplicação de plantas-matrizes produtivas e de qualidade, permitindo selecionar características que sejam desejáveis para a evolução dos pomares e o possível incremento da produção.

No entanto, estudos sobre estaquia são poucos, limitando-se apenas à espécie principal, o maracujá-amarelo, sendo eventualmente estudada noutras espécies. Foi observado por Graça (1990) e Salomão et al. (2002), no maracujá-amarelo, um enraizamento superior a 90\%. Outra espécie que também teve resultados promissores foi o maracujá-doce ( $P$. alata Dyander), com 94\% de enraizamento (Salomão et al., 2002). Entretanto, estudos posteriores devem ser feitos para a melhoria da técnica, com a criação de protocolos para formação de mudas e, por fim, a recomendação aos produtores.

O objetivo deste trabalho foi avaliar o enraizamento de estacas no inverno e no verão, utilizando diferentes concentrações de AIB nas espécies $P$. giberti, $P$. nitida, $P$. setacea D.C., maracujá-amarelo e doce.

\section{MATERIAL E MÉTODOS}

A área experimental pertence ao Departamento de Produção Vegetal da Faculdade de Ciências Agrárias e
Veterinárias, Universidade Estadual Paulista (FCAV/UNESP), Câmpus de Jaboticabal, cujas coordenadas geográficas são: latitude $21^{\circ} 17^{\prime} 05^{\prime \prime S}$ e longitude $48^{\circ} 17^{\prime} 09^{\prime \prime} \mathrm{W}$, altitude de aproximadamente $590 \mathrm{~m}$. O clima da região, segundo classificação de Koppen é do tipo Cwa, subtropical, relativamente seco no inverno, com chuvas no verão, apresentando temperatura média anual de $22^{\circ} \mathrm{C}$ e precipitação de $1.552 \mathrm{~mm}$.

O trabalho foi conduzido no período de julho de 2001 a março de 2002, em câmara de nebulização intermitente sob telado (50\% de luminosidade). As matrizes das espécies $P$. alata, $P$. giberti, $P$. nitida e $P$. setacea pertencem ao Banco de Germoplasma Ativo (BAG), do Departamento de Produção Vegetal. As estacas de maracujá-amarelo foram provenientes de pomares próximos, em propriedades rurais, nos municípios de Jaboticabal-SP (aproximadamente 10km) e Taquaritinga-SP (aproximadamente 30 $\mathrm{km})$, pomares estes em estádio inicial de produção de frutos.

Plantas-matrizes foram selecionadas em função de sanidade, produtividade, vigor vegetativo, frutos com boas características agronômicas. Foram coletadas, em julho de 2001 e janeiro de 2002, estacas herbáceas da porção mediana de ramos em estádio de crescimento vegetativo. Foram preparadas estacas com cerca de $15 \mathrm{~cm}$ de comprimento e $4 \mathrm{~mm}$ de diâmetro, preservando-se 3 nós ou gemas vegetativas e duas folhas cortadas ao meio, além de executar um corte em bisel na extremidade basal e um corte perpendicular na parte apical da estaca para evitar acúmulo de água e, conseqüentemente, o apodrecimento da estaca.

As estacas foram tratadas com AIB (ácido indolbutírico) substância pura, nas concentrações 0; 500; 1.000, 2.000mg.L ${ }^{-1}$, através da imersão da base das estacas (1,5 a 2,5cm), por um período em torno de 5 segundos. Foi preparada uma solução de AIB para $500 \mathrm{~mL}$ (na solução contendo $1.000 \mathrm{mg} . \mathrm{L}^{-1}$ ), dissolvendose $500 \mathrm{mg}$ da substância pura em $250 \mathrm{~mL}$ de álcool etílico, agitandose bem e adicionando-se água destilada até completar o volume. Essa solução alcoólica a 50\% é melhor para dissolver o AIB, pois, quando se usa uma quantidade muito pequena de álcool, pode ocorrer a precipitação do AIB ao se adicionar água destilada. Após, as estacas foram acondicionadas em bandejas plásticas perfuradas, de dimensões 40x30x10cm, contendo vermiculita de textura média, e submetida ao regime de irrigação por sistema de nebulização intermitente (45 segundos desligado, 15 segundos ligado). O tempo de permanência na câmara de nebulização foi de 60 dias, quando foram feitas as avaliações: percentagem de estacas enraizadas, que consistiu na contagem das estacas que emitiram, pelo menos, uma raiz, independentemente do desenvolvimento da mesma, expressando o resultado em percentagem de enraizamento; percentagem de estacas sobreviventes, que consistiu na contagem das estacas que permaneceram verdes, expressando o resultado em percentagem de sobrevivência; número e comprimento de raízes/estaca, onde se contaram as raízes formadas nas estacas em cada repetição e mediram-se as cinco raízes mais longas, obtendo-se o número e o comprimento médio de raízes/estaca/repetição.

O delineamento experimental utilizado foi o de blocos ao acaso, com três repetições e 20 estacas por parcela, em esquema fatorial 5x4x2, sendo os fatores: espécies (P. edulis f. flavicarpa, 
P. alata, $P$. nitida, $P$. giberti e $P$. setacea), concentrações de IBA ( $0 ; 500 ; 1.000$ e $2.000 \mathrm{mg}^{-L^{-1}}$ ) e épocas (verão e inverno). Os dados foram submetidos à análise de variância, utilizando-se para o teste $\mathrm{F}$, o nível de $5 \%$ e $1 \%$ de probabilidade, executados no Sistema para Análises Estatísticas (ESTAT) do Pólo Computacional do Departamento de Ciências Exatas da FCAV/ UNESP. As médias foram comparadas entre si, pelo teste de Tukey, ao nível de 5\% e 1\% de probabilidade. As variáveis percentagem de enraizamento e percentagem de sobrevivência foram transformadas por arco-seno $\sqrt{X+0,5 / 100}$, e o número e comprimento de raízes por arco-seno $\sqrt{X+0,5}$.

\section{RESULTADOS E DISCUSSÃO}

Na análise de variância (Tabelas 1), observa-se que a espécie e a concentração de IBA foram significativas para a percentagem de enraizamento, assim como a interação espécie e época. Em linhas gerais, a espécie que enraizou melhor, foi a $P$. giberti, no verão, e a melhor concentração foi zero (testemunha). O número e o comprimento médio de raízes foram maiores no verão, já a sobrevivência de estacas não foi diferente estatisticamente (Tabela 2).

Na tabela 3, encontra-se a percentagem de enraizamento de estacas no inverno e verão para as diferentes espécies e concentrações de IBA. Observa-se que, no $P$. edulis f. flavicarpa, o enraizamento no verão foi baixo (23,33\%), quando comparado ao $P$. giberti, que foi de $73,33 \%$, também no verão. O $P$. alata apresentou enraizamento de 58,33\%, e o $P$. nítida, 40\%, no inverno.

De acordo com Feichtinger Júnior (1985), o enraizamento para o $P$. edulis f. flavicarpa, em agosto, foi de $80 \%$, mas, em junho, o enraizamento foi de apenas 30\%. Neste sentido, Oliveira et al. (2002) observaram $75 \%$ de enraizamento por dois anos consecutivos, no mês de agosto. Entretanto, Graça (1990) obteve 82,5\% em junho, mostrando que, mesmo sendo em uma época desfavorável, com baixa temperatura e crescimento lento das plantas- matrizes, e conseqüentemente baixa síntese de auxinas (fitormônio do enraizamento), é possível conseguir enraizamento nesta época.

Segundo Graça (1990) e Almeida et al. (1991), a primavera é a época favorável para o enraizamento de estacas de maracujáamarelo, conseguindo resultado superior a $90 \%$ de enraizamento. Também no maracujá-doce, Salomão et al. (2002) obtiveram sucesso nesta época (94\%). Deve-se ressaltar que o enraizamento de estacas foi baixo no verão, nestas espécies, o que já havia sido observado por Lima et al. (2000) no maracujá-doce. Entretanto, Gonzales et al. (1989) conseguiram 99,86\% no maracujá-amarelo nesta época.

O P. nitida enraizou no inverno, com $40 \%$, resultado semelhante ao obtido por Melo (1999), com 25\% nesta mesma época. Salienta-se que a época favorável para o enraizamento de estacas para esta espécie é a primavera, quando o crescimento vegetativo está retomando, ocasionando provavelmente um aumento na síntese de auxina. Este fato foi observado por Pereira et al. (1998), que obtiveram 78\% de enraizamento na primavera.
O maracujá-doce ( $P$. alata) enraizou no inverno, com $58,33 \%$ e foi superior em relação ao maracujá-amarelo e $P$. nitida. Segundo Cereda \& Papa (1989) e Meletti \& Nagai (1992), 75\% das estacas enraizaram nessa época, para o maracujá-doce, e para Lima et al. (2000), o enraizamento de estacas foi de 97,11\%, também no maracujá-doce. É um resultado muito favorável para o maracujá-doce, pois se trata de uma espécie pouco domesticada e, mesmo sendo considerada comercial, seu cultivo é recente (5\% da área cultivada), apresentando ampla variabilidade genética. Sendo assim, a produção caracteriza-se por ser heterogênea, apresentando plantas pouco produtivas e de frutos menores, além de baixa resistência a doenças. Com isso, a estaquia pode ser interessante por permitir a clonagem de plantas desta espécie, selecionando-se aquelas de melhor produção, qualidade de frutos e resistência a doenças.

Um aspecto importante nessa espécie é a baixa germinação das sementes para a obtenção das mudas, ocasionado pelo mecanismo de entrada de dormência. O período de armazenamento de sementes é curto, na maioria das vezes, valorizando a produção de mudas por estaquia, como alternativa ao método de obtenção de mudas utilizado pelos produtores (por sementes).

As estacas da espécie $P$. setacea não enraizaram, demonstrando a dificuldade de enraizamento intrínseca da espécie, mesmo considerando que foi testado em época desfavorável, o inverno. O verão parece ser a época mais favorável, conforme foi relatado por Gonzales et al. (1989) e Graça (1990). No presente trabalho, verificou-se que, dentre as espécies testadas, a $P$. edulis f. flavicarpa também mostrou dificuldade em enraizar nesta época do ano. Sugere-se que a $P$. setacea seja estudada separadamente, pois algum fator limitante impediu seu enraizamento. Foi observado alto grau de lignificação dos ramos vegetativos, que impedem a emissão dos primórdios radiculares, ultrapassando este tecido lignificado e não efetivando o enraizamento. Supõe-se que a ruptura da casca (cortes da casca na base da estaca), na ocasião da instalação do experimento, poderia melhorar essa taxa de enraizamento (Fachinello et al., 2005).

TABELA 1 - Percentagem de enraizamento das diferentes espécies em relação às épocas. Jaboticabal-SP, 2001 e 2002.

\begin{tabular}{lcccc}
\hline & \multicolumn{3}{c}{ Épocas } & \multicolumn{1}{c}{} \\
\cline { 2 - 5 } Espécies & Julho 2001 & Janeiro 2002 & $4,27^{*}$ & 7,19 \\
\hline P. nitida & $20,62 \mathrm{Ba}$ & $13,16 \mathrm{BCb}$ & $49,23^{* *}$ & \\
P. alata & $37,64 \mathrm{Aa}$ & $12,32 \mathrm{BCb}$ & $114,90^{* *}$ & \\
P. giberti & $7,32 \mathrm{Cb}$ & $46,00 \mathrm{Aa}$ & $0,00 \mathrm{NS}$ & \\
P. edulis & $19,37 \mathrm{Ba}$ & $19,36 \mathrm{Ba}$ & $0,00 \mathrm{NS}$ & \\
P. setacea & $4,05 \mathrm{Ca}$ & $4,05 \mathrm{Ca}$ & & \\
\hline F & $26,99^{* *}$ & $39,60^{* *}$ & & \\
D.M.S. & 10,08 & & & \\
C.V. $(\%)$ & 48,06 & & & \\
\hline
\end{tabular}

Médias seguidas pela mesma letra, minúscula na horizontal e maiúscula na vertical, não diferem entre si, pelo teste de Tukey a $5 \%$. 
TABELA 2- Comportamento das diferentes espécies, épocas e concentrações de AIB quanto à percentagem de enraizamento, sobrevivência, número e comprimento médio de raízes. Jaboticabal-SP, 2001 e 2002.

\begin{tabular}{lcccc}
\hline Espécie & \% Enraizamento & \% Sobrevivência & $\mathrm{N}^{0}$ Raízes & Compr. Raízes \\
\hline P. nitida & $16,89^{1 /} \mathrm{C}$ & $21,31 \mathrm{~B}$ & $2,28 \mathrm{~A}$ & $1,99 \mathrm{~A}$ \\
P. alata & $24,98 \mathrm{AB}$ & $34,73 \mathrm{~A}$ & $2,13 \mathrm{~A}$ & $1,91 \mathrm{~A}$ \\
P. giberti & $26,66 \mathrm{~A}$ & $28,39 \mathrm{AB}$ & $2,79 \mathrm{~A}$ & $1,97 \mathrm{~A}$ \\
P. edulis & $19,36 \mathrm{BC}$ & $31,24 \mathrm{~A}$ & $2,62 \mathrm{~A}$ & $2,11 \mathrm{~A}$ \\
P. setacea & $4,05 \mathrm{D}$ & $4,05 \mathrm{C}$ & $0,71 \mathrm{~B}$ & $0,71 \mathrm{~B}$ \\
\hline F & $24,62^{* *}$ & $36,06^{* *}$ & $14,17^{* *}$ & $12,49^{* *}$ \\
D.M.S. & 7,13 & 8,01 & 0,87 & 0,65 \\
Época & & & & \\
\hline Inverno & $17,80 \mathrm{~A}$ & $27,57 \mathrm{~A}$ & $1,62 \mathrm{~B}$ & $1,50 \mathrm{~B}$ \\
Verão & $18,98 \mathrm{~A}$ & $22,32 \mathrm{~A}$ & $2,59 \mathrm{~A}$ & $1,98 \mathrm{~A}$ \\
\hline F & $0,53^{\mathrm{NS}}$ & $3,20^{\mathrm{NS}}$ & $24,39^{* *}$ & $10,56^{* *}$ \\
D.M.S. & 3,21 & 3,61 & 0,39 & 0,29 \\
AIB & & & & \\
\hline 0 & $25,41 \mathrm{~A}$ & $32,20 \mathrm{~A}$ & $1,92 \mathrm{~A}$ & $1,81 \mathrm{~A}$ \\
500 & $16,13 \mathrm{~B}$ & $21,92 \mathrm{~B}$ & $2,22 \mathrm{~A}$ & $1,82 \mathrm{~A}$ \\
1.000 & $18,54 \mathrm{~B}$ & $22,40 \mathrm{~B}$ & $2,19 \mathrm{~A}$ & $1,88 \mathrm{~A}$ \\
2.000 & $13,49 \mathrm{~B}$ & $19,27 \mathrm{~B}$ & $2,10 \mathrm{~A}$ & $1,44 \mathrm{~A}$ \\
\hline F & $10,03^{* *}$ & $9,80^{* *}$ & $0,48^{\mathrm{NS}}$ & $1,91^{\mathrm{NS}}$ \\
D.M.S. & 6,00 & 6,73 & 0,73 & 0,55 \\
C.V. $(\%)$ & 48,06 & 41,45 & 51,00 & 46,35 \\
\hline
\end{tabular}

Letras iguais na coluna não diferem entre si, pelo teste de Tukey a $1 \%$.

TABELA 3 - Percentagem de enraizamento em cinco espécies de maracujazeiro, utilizando diferentes concentrações de AIB, no inverno e no verão. Jaboticabal-SP, 2003.

\begin{tabular}{lcccccccc}
\hline & \multicolumn{7}{c}{ Época } \\
\cline { 2 - 9 } & \multicolumn{7}{c}{ Julho 2001 } \\
\cline { 2 - 9 } & $\mathbf{0}$ & $\mathbf{5 0 0}$ & $\mathbf{1 0 0 0}$ & $\mathbf{2 0 0 0}$ & $\mathbf{0}$ & $\mathbf{5 0 0}$ & $\mathbf{1 . 0 0 0}$ & $\mathbf{2 . 0 0 0}$ \\
\hline \multicolumn{1}{c}{ Espécie } & $\mathbf{0}$.00ncentrações de AIB \\
\hline P. edulis & $21,67^{*}$ & 15,00 & 10,00 & 5,00 & 23,33 & 5,00 & 11,67 & 11,67 \\
P. alata & 58,33 & 18,33 & 50,00 & 25,00 & 8,33 & 1,67 & 18,33 & 0,00 \\
P. giberti & 3,33 & 0,00 & 1,67 & 3,33 & 73,33 & 60,00 & 38,33 & 33,33 \\
P. nitida & 40,00 & 6,77 & 10,00 & 8,33 & 10,00 & 11,67 & 3,33 & 1,67 \\
P. setacea & 0,00 & 0,00 & 0,00 & 0,00 & 0,00 & 0,00 & 0,00 & 0,00 \\
\hline
\end{tabular}

* Dados não-transformados.

\section{CONCLUSÕES}

1-Passiflora giberti e P. alata apresentaram melhor enraizamento em relação a $P$. edulis f. flavicarpa, $P$. nitida e $P$. setacea.

2-A utilização de AIB não proporcionou efeito significativo no enraizamento.

3-O número e o comprimento de raízes foram maiores no verão.

\section{REFERÊNCIAS}

ALMEIDA, L.P. de; BOARETTO, M.A.C.; SANTANA, R.G. de. Estaquia e comportamento de maracujazeiros (Passiflora edulis Sims f. flavicarpa Degener) propagados por via sexual e vegetativa. Revista Brasileira de Fruticultura, Jaboticabal, v.13, n.1, p.157-159, 1991.

CEREDA, E.; PAPA, R.C.R. Enraizamento de estacas das espécies de maracujazeiro P. alata Dryand e Passiflora edulis Sims f. flavicarpa Degener sob nebulização. In: CONGRESSO BRASILEIRO DE FRUTICULTURA, 10., 1989, Fortaleza. Anais... Fortaleza: Sociedade Brasileira de Fruticultura, 1989. p.375-378.

FACHINELLO, J.C.; HOFFMANN, A.; NACHTIGAL, J.C. Propagação de plantas frutíferas. Brasília: Embrapa Informação Tecnológica, 2005. 221p.

FEICHTINGER JÚNIOR, W. Enraizamento de diferentes tipos de estacas enfolhadas de maracujazeiro (Passiflora edulis Sims f. flavicarpa Degener) em câmara de nebulização. 1985. 50 f. Monografia (Trabalho de Graduação em Agronomia) - Faculdade de Ciências Agrárias e Veterinárias, Univesidade Estadual Paulista, Jaboticabal, 1985.

GONZALEZ, G.; RODRIGUEZ, J.; SOURD, D. Evaluacion de la propagacion por semillas y esquejes en Passiflora edulis var. flavicarpa. Agrotecnia de Cuba, Havana, v.21, n.1, p.107-109, 1989.

GRAÇA, J. Estudo sobre a propagação do maracujazeiro (Passiflora edulis Sims f. flavicarpa Degener) através de sementes e estacas. 1990. 92 f. Dissertação (Mestrado em Produção Vegetal) - Faculdade de Ciências Agrárias e Veterinárias, Universidade Estadual Paulista, Jaboticabal, 1990.

IBGE - Instituto Brasileiro de Geografia e Estatística. Produção Agrícola Municipal. Maracujá. Brasília: Ministério do Planejamento, Orçamento e Gestão, 2007.

LIMA, E. de S.; CORRÊA, L. de S.; BOLIANI, A.C. Épocas de plantio, tipos de estacas e concentrações de ácido indolbutírico, no enraizamento de estacas de maracujazeiro-doce (Passiflora alata Dryander). In: CONGRESSO BRASILEIRO DE FRUTICULTURA, 16., 2000, Fortaleza. Anais... Fortaleza: Sociedade Brasileira de Fruticultura, 1989. p.486.

MELETTI, L.M.M.; NAGAI, V. Enraizamento de estacas de sete espécies de maracujazeiro (Passiflora spp). Revista Brasileira de Fruticultura, Jaboticabal,, v.14, n.2, p.163-168, 1992.

MELO, A.L. de. Métodos de quebra de dormência, e de armazenamento de sementes, e aspectos de obtenção de mudas de maracujá-suspiro (Passiflora nitida H.B.K.). 1999. 95 f. Tese (Doutorado em Agronomia, Área de Produção Vegetal) Faculdade de Ciências Agrárias e Veterinárias, Universidade Estadual Paulista, Jaboticabal, 1999.

OLIVEIRA, J.A. de; JUNQUEIRA, N.T.V.; PEIXOTO, J.R.; PEREIRAA.V. Efeito dos substratos artificiais no enraizamento e no desenvolvimento de estacas de maracujazeiro-azedo 
(Passiflora edulis Sims f. flavicarpa Deg.). Revista Brasileira de Fruticultura, Jaboticabal, v.24, n.2, p.505-508, 2002.

PEREIRA, F.M.; OLIVEIRA, J.C.; NACHTIGAL, J.C. Propagação vegetativa do maracujá-suspiro (Passiflora nitida) por meio de estacas herbáceas. In: SIMPÓSIO BRASILEIRO SOBRE A CULTURADO MARACUJAZEIRO, 5., 1998, Jaboticabal. Anais... Jaboticabal: FUNEP, 1998. p.313.
RUGGIERO, C.; OLIVEIRA, J.C. de. Enxertia do maracujazeiro. In: SIMPÓSIO BRASILEIRO SOBRE A CULTURA DO MARACUJAZEIRO, 5., 1998, Jaboticabal. Anais... Jaboticabal: FUNEP, 1998. p.70-92.

SALOMÃO, L.C.C.; PEREIRA, W.E.; DUARTE, R.C.C.; SIQUEIRA, D.L.D. Propagação por estaquia dos maracujazeirosdoce (Passiflora alata Dryand.) e amarelo (P. edulis f. flavicarpa Deg.). Revista Brasileira de Fruticultura, Jaboticabal, v.24, n.1, p.163-167, 2002. 